\title{
Retomadas anafóricas de objeto direto em português brasileiro escrito
}

\section{Anaphoric direct object in written Brazilian Portuguese}

\author{
Gabriel de Ávila Othero \\ Universidade Federal do Rio Grande do Sul - UFRGS \\ gabriel.othero@ufrgs.br \\ Camila Schwanke \\ Pontifícia Universidade Católica do Rio Grande do Sul - PUCRS \\ camilaschwanke@gmail.com
}

Resumo: Os clíticos acusativos de $3^{\mathrm{a}}$ pessoa estão em desuso na fala vernacular em português brasileiro (PB), cedendo espaço para outras duas estratégias de retomada anafórica na função de objeto direto: (a) o pronome pleno ('ele', 'ela') e (b) uma categoria vazia (cf. DUARTE, 1989, 1993; CYRINO, 1997, 2003). A escolha pela retomada anafórica de objeto com pronome ou categoria vazia não é aleatória. A literatura corrente sobre o assunto chama a atenção para o fato de que há uma tendência forte à ocorrência de um fenômeno de distribuição complementar, condicionada por traços semânticos do referente sendo retomado. Há duas hipóteses principais para explicar o fenômeno: (i) a hipótese dos traços de animacidade e especificidade do referente (CYRINO, 1993, 1994/1997; SCHWENTER; SILVA, 2002, entre outros) e (ii) a hipótese do gênero semântico (CREUS; MENUZZI, 2004). Com o objetivo de verificar se essas estratégias relativamente inovadoras e mais comuns em língua falada, a saber, pronomes plenos e objetos nulos, já estão consagradas, ou ao menos presentes de maneira significativa em língua escrita, este trabalho se dedica a uma análise de corpora de jornais 
populares e de redações escolares. Nossos resultados mostram que o clítico tem a tendência de se manter no discurso escrito. Com relação ao uso do objeto nulo, a hipótese do gênero semântico parece promissora, pois explica o fenômeno de retomada anafórica de uma forma mais econômica, por meio de um único traço, e de uma forma mais natural, pois diz respeito a um processo de concordância entre antecedente e forma anafórica.

Palavras-chave: retomada anafórica; objeto nulo; português brasileiro; língua escrita.

Abstract: The accusative clitics for the third person have fallen into disuse in spoken Brazilian Portuguese giving room to two strategies to recover an anaphoric element in a direct object position for the third person: (a) the use of the 'full pronoun' and (b) the use of an empty category. The choice of using a pronoun or a null object is not random. The literature points to the fact that there is a very strong tendency towards a phenomenon of complementary distribution, which is constrained by semantic and discourse features of the referent being recovered. There are two main hypotheses to explain the phenomenon: (i) the features of animacy and specificity of the referent (cf. CYRINO, 1993, 1994/1997; SCHWENTER; SILVA, 2002 among others) and (ii) the semantic gender feature (CREUS; MENUZZI, 2004).In order to verify whether these relatively innovative strategies, i.e. full pronouns and null objects, have already been established, or at least are present in written standard language in a significant way, we analyze corpora from popular newspapers and from school essays. Our results show that the clitic pronoun remains in written discourse. When it comes to the null object, the assumption of semantic gender feature seems promising, because it explains the anaphoric recovery phenomenon in an economic way, from a single feature, and in a more natural way, as it concerns an agreement process between the preceding element and the anaphoric form.

Keywords: anaphor; null object; Brazilian Portuguese; written language.

Recebido em 18 de janeiro de 2017.

Aprovado em 24 de abril de 2017. 


\section{Introdução}

Em português brasileiro (PB), a retomada anafórica de um referente de $3^{\text {a }}$ pessoa na função de objeto direto pode ser realizada (i) por pronome clítico ('o', 'a'), (ii) por pronome pleno ('ele', 'ela') ou (iii) por uma categoria vazia (um objeto nulo, $\mathrm{ON}$ ), como demonstramos nos exemplos a seguir. ${ }^{1}$

(1) As botas dos meninos não davam conta de protegê-los.

(2) Um ladrão tinha entrado [...] Tranquei ele como a um rato.

(3) Ela mostrou ferimentos no corpo e atribuiu $\emptyset$ ao marido.

Enquanto a primeira estratégia (a retomada com o clítico) é marca de discurso monitorado em PB, as duas últimas estratégias são relativamente inovadoras e mais comuns em língua falada ou escrita não monitorada (CYRINO, 1994/1997; MONTEIRO, 1994; SCHWENTER; SILVA, 2002; OTHERO; CARDOZO, 2017). Em estudos diacrônicos do português, pesquisadores como Tarallo (1983), Duarte (1989) e Nunes (1996) mostraram que os clíticos estão em desuso e que, em seu lugar, o ON e o pronome pleno são as principais estratégias para a retomada anafórica de objeto direto de terceira pessoa na gramática do PB.

Entretanto, a escolha entre objeto nulo vs. pronome não se dá de forma aleatória. Como diversos trabalhos na literatura sobre o assunto demonstram (cf. referências citadas no parágrafo anterior, por exemplo), há uma tendência muito forte de este ser um fenômeno de distribuição complementar (ou que está se encaminhando para a distribuição complementar - cf. OTHERO et al., 2016), condicionado por traços semântico-pragmáticos do antecedente retomado. Na literatura sobre o ON, encontramos, basicamente, duas hipóteses em relação aos traços semântico-pragmáticos do antecedente que funcionariam como condicionadores da escolha entre pronomes $v s$. ONs na sua retomada

\footnotetext{
${ }^{1}$ Todos os exemplos que apresentamos no texto foram extraídos do nosso corpora. Estamos considerando aqui apenas a distinção entre pronomes e categoria vazia na retomada do objeto; um referente pode também ser retomado, evidentemente, por um SN\DP "completo", como em "Encontrei a Maria, mas não falei com essa moça sobre suas faltas" (cf., por exemplo, OLIVEIRA, 2007; VIEIRA-PINTO; COELHO, 2016).
} 
anafórica, a saber, a hipótese dos traços de animacidade e especificidade (DUARTE, 1989; CYRINO, 1994/1997; SCHWENTER; SILVA, 2003) e a hipótese do gênero semântico (CREUS; MENUZZI, 2004, PIVETTA, 2015; AYRES, 2016, OTHERO et al., 2016).

A fim de verificar se essas duas estratégias relativamente inovadoras e mais comuns em língua falada (i.e. ON e pronome pleno em função de objetos diretos) já estão presentes de maneira significativa em língua escrita padrão, nosso trabalho traz uma análise de corpora de jornais populares - Jornal Diário Gaúcho e Jornal Massa! - e de 88 redações escolares infantis de $1^{\mathrm{a}}$ a $4^{\mathrm{a}}$ série do Ensino Fundamental, também para investigar como se dá a retomada anafórica no processo de desenvolvimento do PB escrito e do efeito da escolarização sobre o processo.

Nossa hipótese é de que o uso de ONs já deve aparecer na escrita, ainda que os clíticos representem a principal estratégia de retomada anafórica. Buscamos analisar nossos dados apoiados em duas hipóteses existentes na literatura sobre o condicionamento da retomada anafórica de objetos diretos em PB, acreditando que a tese do traço de gênero semântico deve explicar o fenômeno da distribuição entre categoria vazia $v s$. pronome de maneira mais adequada ou mais econômica. Nesse sentido, quando o antecedente tiver gênero semântico, será retomado por um pronome; caso contrário, será preferencialmente retomado por um ON.

Organizamos o texto da seguinte maneira: na seção1, caracterizamos o objeto nulo e discorremos sobre os tipos de retomada anafórica de objeto direto de $3^{\mathrm{a}}$ pessoa em PB. Além disso, apresentamos as duas hipóteses encontradas na literatura em relação aos traços semântico-pragmáticos que parecem ser condicionadores da escolha entre pronomes vs. ONs. Na seção 2, apresentamos os corpora utilizados, explicamos nossa metodologia e analisamos os resultados encontrados. Finalmente, dedicamos a terceira seção à discussão de alguns casos interessantes, que não "se comportam" de acordo com as previsões da hipótese do gênero semântico e, além disso, observamos princípios discursivos particulares que exercem influência sobre essas retomadas anafóricas. Em seguida, tecemos nossas considerações finais. 


\section{Objeto nulo e retomada anafórica}

A retomada anafórica ocorre quando fazemos referência a um elemento do discurso já mencionado previamente. Em PB, a retomada anafórica de um referente de $3^{\mathrm{a}}$ pessoa na função de objeto direto pode ser realizada por pronome clítico ('o', 'a'), por pronome pleno ('ele', 'ela') ou por uma categoria vazia (um ON), como vimos, anteriormente, nos exemplos (1) a (3) (ver também observação da nota 2).

Cyrino (1994/1997), em seu clássico trabalho sobre ON em PB mostrou que, desde o século XIX, podemos atestar uma mudança diacrônica em relação ao quadro pronominal brasileiro. Os clíticos acusativos de terceira pessoa ('o', 'a') estão em um processo de declínio ${ }^{2}$ e vêm cedendo espaço para os pronomes plenos ('ele', 'ela') e para a estratégia de retomada anafórica com objeto nulo. ${ }^{3}$ Conforme Cyrino, o objeto nulo, isto é, a possibilidade de realização de um elemento vazio, foneticamente nulo, na função de objeto, sempre foi possível em português, mas passou por um crescimento significativo nos últimos séculos, como podemos observar nas seguintes tabelas:

TABELA 1 - Objetos nulos no tempo

\begin{tabular}{c|c|c|c|c|c}
\hline & $\begin{array}{c}\mathbf{1}^{\text {a }} \text { metade do } \\
\text { século XVIII }\end{array}$ & $\begin{array}{c}\mathbf{1}^{\text {a }} \text { metade do } \\
\text { século XIX }\end{array}$ & $\begin{array}{c}\mathbf{2}^{\text {a }} \text { metade do } \\
\text { século XIX }\end{array}$ & $\begin{array}{c}\mathbf{1}^{\text {a }} \text { metade do } \\
\text { século XX }\end{array}$ & $\begin{array}{c}\mathbf{2}^{\text {a }} \text { metade do } \\
\text { século XX }\end{array}$ \\
\hline $\begin{array}{c}\text { Objetos nulos } \\
(\%)\end{array}$ & $14,2 \%$ & $41,6 \%$ & $23,2 \%$ & $69,5 \%$ & $81,1 \%$ \\
\hline $\begin{array}{c}\text { Formas nulas } \\
(\%)\end{array}$ & Século XVI & Século XVII & Século XVIII & Século XIX & Século XX \\
\hline $\begin{array}{c}\text { Formas } \\
\text { Preenchidas } \\
(\%)\end{array}$ & $89,3 \%$ & $87,4 \%$ & $81,5 \%$ & $55 \%$ & $20,9 \%$ \\
\hline
\end{tabular}

Fonte: Cyrino, 1993, p. 165.

${ }^{2}$ Cf. também Tarallo (1983).

${ }^{3}$ A esse respeito, ver também Monteiro (1994) e Bagno (2011). 
Os dados de Cyrino (1994/1997) foram coletados a partir de textos escritos de peças teatrais. A autora, com o intuito de procurar textos que representassem o português oral, optou pelo gênero comédia ou por autores considerados "populares" pela literatura, visto que suas obras provavelmente refletiam a linguagem popular da época. ${ }^{4}$

Como se percebe na Tabela 1 a queda do pronome clítico parece estar ligada ao fenômeno do objeto nulo, uma vez que as formas nulas na função de objeto direto cresceram significativamente (de 10,7\% no século XVI para $79,1 \%$ no século XX), ao passo que as formas preenchidas caíram para apenas $20,9 \%$ no século XX, o que pode ser observado também no Gráfico 1, a seguir.

GRÁFICO 1 - Correlação entre pronomes e objetos nulos ao longo do tempo

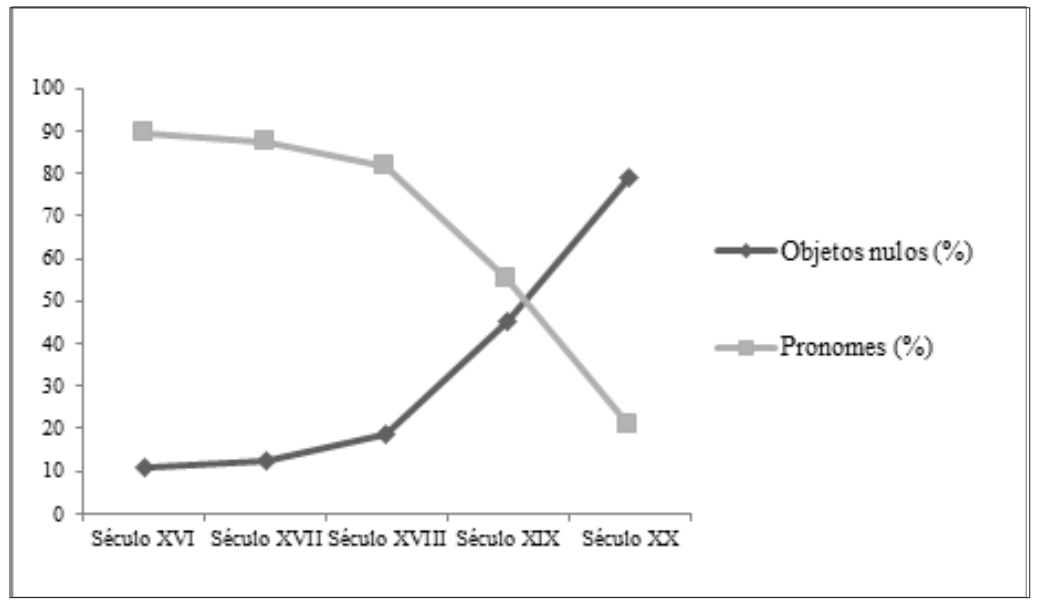

Fonte: Cyrino, 1994/1997.

Para Creus e Menuzzi (2004, p. 5), a mudança mais significativa é que os

ONs passaram de praticamente inexistentes a praticamente categóricos do século XVIII ao XX, período de reorganização da gramática do $\mathrm{PB}$ em relação ao sistema

\footnotetext{
${ }^{4}$ Constituem o corpus do trabalho de Cyrino as seguintes peças: "Rua Alegre, 12" (1940), "O Pagador de Promessas" (1959), "Um Grito Parado no Ar" (1973) e "No Coração do Brasil”" (1992).
} 
de anáfora pronominal de objeto. O aumento do uso de objeto nulo como estratégia preferencial de retomada anafórica indica [...] sinal de reanálise radical num curto período de tempo.

O fenômeno do objeto nulo, isto é, "o fato de podermos nos referir a uma categoria apresentada anteriormente na situação discursiva mediante uma categoria foneticamente nula na posição de objeto" (MILESKI, 2014, p. 2) é considerado um dos traços que distingue o PB das demais línguas românicas (cf. CYRINO, 1993; CYRINO; MATOS, 2016, por exemplo).

Poderíamos pensar que as duas estratégias inovadoras de substituição do pronome clítico (ON e pronome pleno) encontramse em variação livre, mas diversos trabalhos na literatura sobre o assunto chamam a atenção para o fato de que há uma tendência, não categórica, mas muito forte, à ocorrência de um fenômeno de distribuição complementar. Essa distribuição estaria condicionada por traços semânticos e discursivos do referente retomado. Para alguns (CYRINO, 1993, 1994/1997; SCHWENTER; SILVA, 2002, etc.), os traços de animacidade e especificidade do antecedente explicariam a distribuição. Alternativamente há a hipótese do gênero semântico (cf. CREUS; MENUZZI, 2004) como condicionador do uso de pronomes plenos e ONs em PB. A seguir, veremos mais detalhadamente esses traços e as hipóteses relacionadas a eles.

\subsection{Os traços semântico-pragmáticos dos antecedentes}

Como mencionamos, a escolha do falante entre pronome vs. objeto nulo não se dá de forma aleatória: os traços semântico-pragmáticos do referente parecem condicionar o tipo de retomada anafórica utilizado. A seguir, definiremos os traços de animacidade, especificidade e gênero semântico.

\subsubsection{Animacidade e especificidade}

$\mathrm{O}$ traço de animacidade é um conceito semântico que diz respeito ao fato de os referentes serem animados ou não. 
Animacidade é uma noção semântica que envolve um conjunto de elementos agrupados por apresentarem a característica de serem animados, o que é diferente do traço humano. O conjunto dos elementos que são animados inclui, além dos seres humanos, os demais seres, que, assim como a espécie humana, apresentam algum tipo de vida, como gatos, cachorros, insetos, peixes, etc. (CASAGRANDE, 2007, p. 52)

Exemplos:

(4) O cachorro apareceu um dia, sem que ninguém o trouxesse, e começou a dar voltas por todos os cantos. [+a]

(5) Não deixe água parada em pratos de plantas. Coloque areia ou troque a água e lave-os com escova duas vezes por semana. [-a]

Já o traço de especificidade é a propriedade de o referente ter uma única identificação no discurso. Conforme Cyrino (c.p. apud PIVETTA, 2015, p. 57), "um objeto direto é específico se, de acordo com a perspectiva do falante, o referente tem uma única identificação. Caso não haja um único referente, não é específico". Enquanto a animacidade é uma característica semântica, inerente ao referente, a especificidade, por sua vez, é característica "discursiva”, i.e. só conseguimos definir se o referente é específico ou não observando o contexto discursivo:

(6) Ela vê o filho e corre para ampará-lo. [+e]

(7) A tevê é atrativa e, sabendo usar, pode ter vantagens. [-e]

Para Cyrino (1994/1997), Matos e Cyrino (2001), Cyrino e Matos (2002) e Schwenter e Silva (2002, 2003), entre outros, os traços de animacidade e especificidade são os responsáveis por condicionar o uso entre pronome e $\mathrm{ON}$ na retomada anafórica em função de objeto em $\mathrm{PB}$, de modo que antecedentes com os traços [+animado] e [+específico] tendem a ser retomados por pronomes, enquanto antecedentes com os traços [-animado] e [-específico] tendem a ser retomados por uma categoria vazia (um ON). A interação entre esses traços, i.e. casos [+a, -e] e [-a, +e], entretanto, costuma ser problemática, com resultados não polarizados. Voltemos aos exemplos (6) e (7): 
(6) Ela vê o filho e corre para ampará-lo/??Ø. [+animado, +específico]

(7) A tevê é atrativa e, sabendo usar ??ela/Ø, pode ter vantagens. [-animado, -específico]

Em (6), o antecedente é "o filho" $[+\mathrm{a},+\mathrm{e}]$, e, por isso, parece mais natural retomá-lo utilizando o pronome clítico "lo"; já em (7), o antecedente tem os traços [-a, -e], e a tendência mais natural aqui é, a nosso ver, a de se fazer a retomada por um objeto nulo. ${ }^{6}$

Schwenter e Silva (2003) realizaram uma análise do corpus do PEUL (Programa de Estudos sobre o Uso da Língua) ${ }^{7}$ a fim de testar a hipótese de que os traços de animacidade e especificidade influenciam no tipo de retomada anafórica de objetos diretos de terceira pessoa. Alguns de seus resultados principais podem ser visualizados na Tabela 2 .

TABELA 2 - Objeto nulo vs. pronome no corpus do PEUL

\begin{tabular}{c|c|c|c}
\hline Traços & ON & Pronomes & Total \\
\hline$+\mathbf{a},+\mathbf{e}$ & $50(28,4 \%)$ & $126(71,6 \%)$ & $176(100 \%)$ \\
\hline$+\mathbf{a},-\mathbf{e}$ & $102(89,5 \%)$ & $12(10,5 \%)$ & $114(100 \%)$ \\
\hline $\mathbf{- a},+\mathbf{e}$ & $151(100 \%)$ & ------- & $151(100 \%)$ \\
\hline $\mathbf{- a},-\mathbf{e}$ & $604(97,9 \%)$ & $13(2,1 \%)$ & $617(100 \%)$ \\
\hline
\end{tabular}

Fonte: Schwenter e Silva, 2003, p. 108.

Os autores concluem que há uma diferença significativa entre os antecedentes $[+\mathrm{a},+\mathrm{e}]$ e os $[+\mathrm{a},-\mathrm{e}]: 71,6 \%$ de preferência por pronomes

\footnotetext{
${ }^{5} \mathrm{Na}$ fala, o mais natural seria retomar o referente com um pronome pleno ('ele'). Mas, como nosso exemplo é de corpus escrito, o clítico é a opção preferida, como veremos na próxima seção.

${ }^{6}$ Apresentamos, nesses dois exemplos, nosso julgamento de aceitabilidade, com base em nossa intuição, obviamente. Entretanto, testes de gramaticalidade e aceitabilidade envolvendo o uso de pronomes e ONs na retomada anafórica já foram empregados por Creus e Menuzzi (2004) e Othero et al. (2016), e os resultados apresentados ali confirmam esses julgamentos.

${ }^{7}$ Corpus compilado por pesquisadores da UFRJ que reúne ocorrências de português falado no Rio de Janeiro no início dos anos de 1980. Foram utilizadas 1.250 ocorrências (cf. SCHWENTER; SILVA, 2003, p. 106).
} 
contra $89,5 \%$ de preferência por ON. Isso pode indicar que o traço de especificidade exerce alguma influência sobre o de animacidade. Por outro lado, a diferença entre os objetos diretos com antecedentes $[-a,+e]$ e $[-a,-e]$ não é relevante, sugerindo não haver influência da especificidade nessa distribuição. Assim, ainda segundo os autores, o traço de animacidade é o principal condicionador a atuar sobre o objeto direto anafórico, ao passo que a especificidade, por sua vez, seria um fator secundário, visto que os resultados não foram tão esclarecedores.

Para Duarte (1989) e Cyrino (1994/1997), o traço de animacidade do antecedente exerce papel fundamental na distribuição de pronomes plenos e ONs em PB. Cyrino (1994/1997) sustenta que o traço de especificidade também seria relevante, mas é o que menos polariza as retomadas anafóricas entre $\mathrm{ON}$ e pronome, apesar de influenciar na escolha entre as duas formas. $\mathrm{O}$ fato é que a interação entre esses dois traços ainda não é totalmente clara. Assim, não temos uma classe natural opositiva clara, i.e., não podemos opor os antecedentes [+a] aos [-a]; tampouco os referentes com o traço $[+\mathrm{e}]$ podem se opor aos referentes [-e]; nem a combinação entre esses dois traços parece explicar a história toda.

Para resolver esse aparente problema na hipótese que envolve os traços de animacidade e especificidade do referente anafórico, Creus e Menuzzi (2004) chamaram a atenção para o fato de que uma distinção com base em um único traço semântico poderia explicar a escolha entre pronomes e ONs: o traço de gênero semântico. É o que veremos a seguir.

\subsubsection{Gênero Semântico}

O traço de gênero semântico diz respeito à classificação que distingue substantivos que denotam seres sexuados de substantivos que denotam seres não sexuados; ou, talvez de forma mais precisa, o traço distingue substantivos que denotam sexo natural aparente, como homem, mulher, professor, cachorro etc., de substantivos que não denotam sexo natural aparente, como mesa, livro, vítima, cônjuge, boneco, tartaruga etc. Referentes inanimados são marcados negativamente para esse traço $;^{8}$ substantivos animados, contudo, não têm necessariamente um gênero semântico específico: pessoa, habitante, estudante etc. Ou seja,

\footnotetext{
${ }^{8}$ Contudo, como ressalta Ayres (2016), na fala de crianças, referentes inanimados podem ter gênero semântico, como Barbie vs. Ken, BonecodoWoody, etc.
} 
alguns substantivos têm gênero gramatical, mas não gênero semântico inerente ${ }^{9}$.A hipótese de Creus e Menuzzi (2004) é, basicamente, de que o traço de gênero semântico do referente atua como gatilho essencial para a retomada anafórica de objetos em terceira pessoa. Para eles,

É claro que, destes dois traços [animacidade e especificidade], o que tem papel central é o de animacidade, já que é ele que configura as generalizações básicas do sistema; o traço de especificidade parece ser relevante, na verdade, apenas para uma classe de antecedentes. Assim, parece-nos que a explicação do sistema de anáfora de objeto em PB [...] precisa identificar no traço de animacidade aquele aspecto essencial que, ao mesmo tempo que traça as generalizações básicas, prevê também a possibilidade de alternativa para os antecedentes animados não-específicos. A nosso ver, o aspecto fundamental do traço de animacidade é que ele está associado com distinções de gênero semântico. (CREUS; MENUZZI, 2004, p.7)

Assim, um único traço seria suficiente para explicar como ocorre a retomada anafórica em $\mathrm{PB}$, de maneira que, se o referente tem o traço [+gs], i.e., tem gênero semântico identificável, é preferencialmente retomado por um pronome; caso contrário, a retomada anafórica tende a ser feita com objeto nulo:

(8) A garota se irritou muito quando a mãe disse que iria levá-la ao Conselho Tutelar.

(9) Juan teve uma ótima chance para matar logo o jogo, mas desperdiçou $\varnothing$.

Em (8), "a garota" tem o traço [+gs], pois o falante "reconhece" o gênero sexual a que pertence o ser denotado por esse referente (note que o referente foi retomado por um pronome). Em (9), "uma ótima chance" não tem gênero semântico, e a retomada anafórica foi feita por uma categoria vazia. De acordo com a hipótese do gênero semântico, é esse traço que determina a escolha entre o pronome e a categoria vazia na realização do objeto direto anafórico. Do ponto de vista conceitual, Creus e Menuzzi acreditam que essa hipótese é mais "natural" que a

${ }^{9}$ Cf. Câmara Jr. (1959) para uma distinção entre gênero semântico e gênero gramatical. 
hipótese de animacidade e especificidade, pelo fato de a opção entre um ON e um pronome pleno se dar por uma questão de concordância entre antecedente e forma anafórica: antecedentes com gênero semântico são retomados preferencialmente por pronomes porque esses pronomes são formas anafóricas especificadas para gênero. Já os antecedentes sem gênero semântico favorecem a retomada por objetos nulos porque ONs são categorias não especificadas para gênero. Dessa maneira, apenas um traço (e não uma combinação de traços) seria suficiente para explicar como ocorre a retomada anafórica em PB.

Passemos, agora, à apresentação dos corpora de análise e aos resultados a que chegamos.

\section{Corpora e análise dos dados}

Nesta seção, falaremos sobre nossos corpora de língua escrita e sobre nossa metodologia de análise, para, então, chegarmos aos resultados obtidos. Dois dos corpora utilizados em nossa pesquisa fazem parte do Projeto Por Popular, encampado na Universidade Federal do Rio Grande do Sul (UFRGS), e o terceiro corpus é resultado do trabalho de Oliveira (2007).

\subsection{Corpora}

O Projeto PorPopular (padrões do português popular escrito), coordenado pela Profa. Dra. Maria José Bocorny Finatto (UFRGS), tem o objetivo de organizar um corpus de jornais populares - destinados a públicos de menor poder aquisitivo - da região Nordeste e Sul do Brasil e disponibilizar o material para uso de pesquisadores. Atualmente, o projeto contém textos do jornal popular Diário Gaúcho $(D G)$ - publicado em Porto Alegre (RS) - e do Jornal Massa!, o primeiro jornal popular da Bahia.

Um dos objetivos do nosso trabalho é verificar se as estratégias relativamente inovadoras e mais comuns de retomadas anafóricas na função de objeto direto em PB (pronomes plenos e objetos nulos) já estão presentes de maneira significativa em língua escrita padrão. Por isso, analisamos 250 textos do Jornal Diário Gaúcho (dos anos de 2008, 2010 e 2013) e 250 textos do Jornal Massa! (de 2012, 2014 e 2015), totalizando 462 páginas. Nossa hipótese é que, por se tratar de textos com estilo "popular" (destinado às classes C e D da população), os redatores 
e jornalistas pudessem incorporar alguns elementos não estigmatizados, mas distintivos da língua falada, tal como a retomada anafórica de objetos por um elemento nulo ou mesmo por pronome pleno. ${ }^{10}$

Além disso, utilizamos também o corpus do trabalho de Oliveira (2007), composto de 88 redações escolares de crianças de $1^{\mathrm{a}}$ a $4^{\mathrm{a}}$ série do Ensino Fundamental de escolas de Curitiba, para averiguarmos como se dá a retomada anafórica no processo de aprendizagem do português brasileiro escrito. ${ }^{11} \mathrm{O}$ objetivo de Oliveira (2007, p. 4) foi "abordar as mudanças ocorridas no português do Brasil, especificamente quanto à alteração do paradigma pronominal para a posição de objeto direto". Para isso, a autora analisou um corpus de 88 textos escolares escritos por crianças de $1^{\mathrm{a}}$ a $4^{\mathrm{a}}$ série do Ensino Fundamental entre os anos de 2002 e 2006 (22 textos de cada série).

Diferentemente do que foi feito em nosso trabalho, que tratou apenas das retomadas com pronomes e objetos nulos, Oliveira se ocupou das seguintes retomadas anafóricas de objeto direto: (i) objeto nulo, (ii) pronome tônico ele/ela, (iii) SN anafórico pleno e (iv) clítico acusativo de $3^{\text {a }}$ pessoa. Além dos traços de animacidade e especificidade do antecedente, a autora observou a natureza morfológica dos verbos (tempos simples ou compostos), a posição do clítico (próclise ou ênclise) e a série em que as crianças estavam. Seus resultados mostram que o ON é a estratégia mais comum nas redações das crianças (52\% das ocorrências de retomada anafórica do objeto aconteceram com uma categoria vazia).

Conforme vemos na Tabela 3, o traço de animacidade é relevante para o condicionamento do ON: 69\% das ocorrências de ON aparecem quando o antecedente apresenta o traço [-animado]. Entretanto, o traço [+animado] também foi significativo nos contextos de ON: em 43\% dos casos de ocorrências de objeto nulo, o antecedente apresenta o traço [+animado].

\footnotetext{
${ }^{10}$ Cf. Kenedy (2016) sobre características da fala vernacular em PB e sua relação com a escrita.

${ }^{11}$ Agradecemos aqui à Profa. Dra. Maria José Finatto por ter gentilmente nos permitido acesso ao corpus do projeto PorPopular e à Profa. Dra. Solange Mendes Oliveira por ter-nos enviado uma lista contendo os dados detalhados de seu corpus.
} 
TABELA 3 - Distribuição das variantes usadas segundo o traço semântico do antecedente

\begin{tabular}{c|c|c|c|c|c|c|c|c|c}
\hline Traço & \multicolumn{2}{|c|}{ Objeto nulo } & \multicolumn{2}{c|}{ Pronome tônico } & \multicolumn{2}{c|}{ SN anafórico } & \multicolumn{2}{c}{ Clítico acusativo } & Total \\
\hline & ocorrências & $\%$ & ocorrências & $\%$ & ocorrências & $\%$ & ocorrências & $\%$ & \\
\hline$[+$ animado $]$ & $47 / 110$ & $\mathbf{4 3}$ & $35 / 110$ & 32 & $5 / 110$ & 4 & $23 / 110$ & 21 & 110 \\
\hline$[$-animado $]$ & $43 / 62$ & $\mathbf{6 9}$ & $4 / 62$ & 6 & $9 / 62$ & 15 & $6 / 62$ & 10 & 62 \\
\hline [outro] & $1 / 2$ & 50 & 0 & 0 & 0 & 0 & $1 / 2$ & 50 & 2 \\
\hline TOTAL & $91 / 174$ & 52 & $39 / 174$ & 23 & $14 / 174$ & 8 & $30 / 174$ & 17 & 174 \\
\hline
\end{tabular}

Fonte: Oliveira, 2007, p. 18 (adaptado).

A pesquisa também mostra que o uso do pronome na função de objeto começa a aparecer nas produções textuais dos alunos apenas nas séries finais, indicando que o grau de escolarização da criança e a normatização podem favorecer o uso de pronomes (especialmente clíticos) em corpus escrito, como vemos na Tabela 4.

TABELA 4 - Ocorrências de pronomes clíticos de $3^{\mathrm{a}}$ pessoa em relação à série da criança

\begin{tabular}{c|c}
\hline \multicolumn{2}{c}{ Clíticos acusativos de $\mathbf{3}^{\mathrm{a}}$ pessoa } \\
\hline Série & $\mathbf{N}^{\mathbf{0}}$ de ocorrências \\
\hline $1^{\mathrm{a}}$ & $3(8 \%)$ \\
\hline $2^{\mathrm{a}}$ & $8(16 \%)$ \\
\hline $3^{\mathrm{a}}$ & $5(11 \%)$ \\
\hline $4^{\mathrm{a}}$ & $14(34 \%)$ \\
\hline Total & $30(100 \%)$ \\
\hline
\end{tabular}

Fonte: Oliveira, 2007, p. 17 (adaptado).

Para Oliveira (2007, p. 23),

A quase não-ocorrência dessa variante nos dados da $1^{\mathrm{a}}$ série ( $8 \%$ ), de crianças com 6 anos de idade, evidencia que os clíticos de $3^{\mathrm{a}}$ pessoa realmente não fazem parte da gramática nuclear da língua e, sim, são adquiridos na 
escola, por meio do ensino formal. Os dados do corpus sugerem que a manutenção dessas formas no PB atual deve-se exclusivamente à ação normativa da escola [...] Isso indica também que o uso dos clíticos acusativos se dá primeiramente na linguagem escrita, via instrução formal. ${ }^{12}$

Ainda segundo os resultados da pesquisa, o traço [+animado] do antecedente favorece o uso do clítico acusativo em $21 \%$, contra $10 \%$ de [-animado]. A ocorrência dessa variante também está relacionada ao traço [+específico] do referente, em 18\% dos casos.

De qualquer forma, o levantamento dos dados de Oliveira (2007) indicou que o objeto nulo é a variante mais utilizada na escrita pelas crianças nas quatro séries investigadas, confirmando sua hipótese inicial de que esta seria a variante preferida por elas - e corroborando os achados de outros estudos com dados de língua infantil, como de Ayres (2016). Além disso, os resultados revelam que, na língua escrita, há sinais de um processo de aprendizagem do uso de clíticos acusativos no final do primeiro segmento da escolarização ( $4^{\mathrm{a}}$ série), algo também observado (ainda que indiretamente) por Bagno (2011) e Kenedy (2016). Por outro lado,

Esse aprendizado [...] não tem a mesma natureza que a aquisição de objetos nulos ou de pronomes tônicos em posição de objeto direto, ou seja, as crianças não precisam ser formalmente ensinadas para internalizar pronomes tônicos ou objetos nulos na posição de objeto, enquanto a aquisição dos clíticos acusativos de $3^{\text {a }}$ pessoa só se dá via instrução formal. (OLIVEIRA, 2007, p. 27)

Passemos agora à nossa metodologia: efetuamos a coleta dos dados, selecionando os objetos diretos anafóricos de $3^{\mathrm{a}}$ pessoa em três formas:

${ }^{12}$ Concordando com esses resultados, os trabalhos de Casagrande (2007) e de Ayres (2016) também trazem resultados sobre a generalização do uso das formas nulas na gramática infantil. Entretanto, esses trabalhos também chamam a atenção para o fato de que a escolarização do falante não é o único fator que influencia o uso de clíticos. Ayres (2016), por exemplo, relata que um falante (de sua pesquisa) em idade préescolar usa mais pronomes clíticos do que tônicos, devido a seu contexto familiar e sócio-econômico elevado. 
a) objeto nulo - categoria vazia na função de objeto;

b) pronome pleno - função de objeto preenchida por um pronome pessoal reto;

c) pronome clítico - emprego de um pronome oblíquo átono para a retomada anafórica de objeto direto.

Coletamos todas as ocorrências de retomada anafórica de objeto direto de $3^{\mathrm{a}}$ pessoa e, para cada ocorrência encontrada, buscamos o referente e analisamos seus traços (animacidade, especificidade e gênero semântico), atribuindo um valor positivo ou negativo.

\subsection{Análise dos dados e resultados}

Nos corpora dos jornais, encontramos um total de 332 ocorrências de retomada anafórica de objeto direto de $3^{\mathrm{a}}$ pessoa. Desse número, 116 referentes foram retomados por objeto nulo, 208 por pronomes clíticos e apenas 8 por pronomes plenos. Do total de ocorrências com pronomes, os clíticos representam 96,3\%, enquanto os pronomes plenos somam apenas 3,7\%. Por isso, na tabela a seguir e em toda a análise dos nossos resultados, juntamos os dois tipos de formas preenchidas na categoria "Pronomes".

TABELA 5 - Total de ocorrências de retomada anafórica nos corpora DG e Massa!

\begin{tabular}{c|c}
\hline Tipo de retomada & Ocorrências \\
\hline Objeto nulo & $116(35 \%)$ \\
\hline Pronomes & $\begin{array}{c}216(65 \%) \\
208(96,3 \%) \text { clíticos } \\
8(3,7 \%) \text { pronomes plenos }\end{array}$ \\
\hline Total & $332(100 \%)$ \\
\hline
\end{tabular}

Fonte: Elaborada pelos autores.

Apesar de haver uma presença significativa de objetos nulos, i.e. um pouco mais de um terço das ocorrências, o pronome clítico ainda é predominante em língua escrita padrão, mesmo na mídia impressa dita popular, como são os jornais Diário Gaúcho e Massa!. O Gráfico 2, a 
seguir, nos permite visualizar melhor a distribuição entre as formas nulas e preenchidas nesses dois corpora:

GRÁFICO 2 - Distribuição entre as formas numas e preenchidas nos corpora analisados

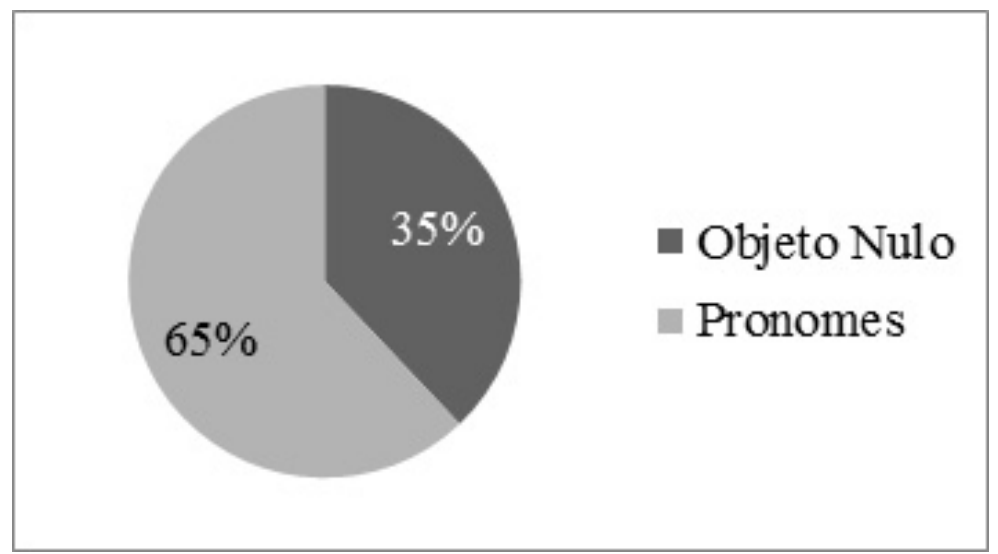

Fonte: Elaborado pelos autores.

Entre o grupo de pronomes, como mencionamos acima, a predominância é entre os pronomes clíticos de $3^{\mathrm{a}}$ pessoa, tal como pode ser visualizado no Gráfico 3, a seguir.

GRÁFICO 3 - Distribuição entre pronomes clíticos e pronomes plenos nos dados totais dos corpora jornalísticos

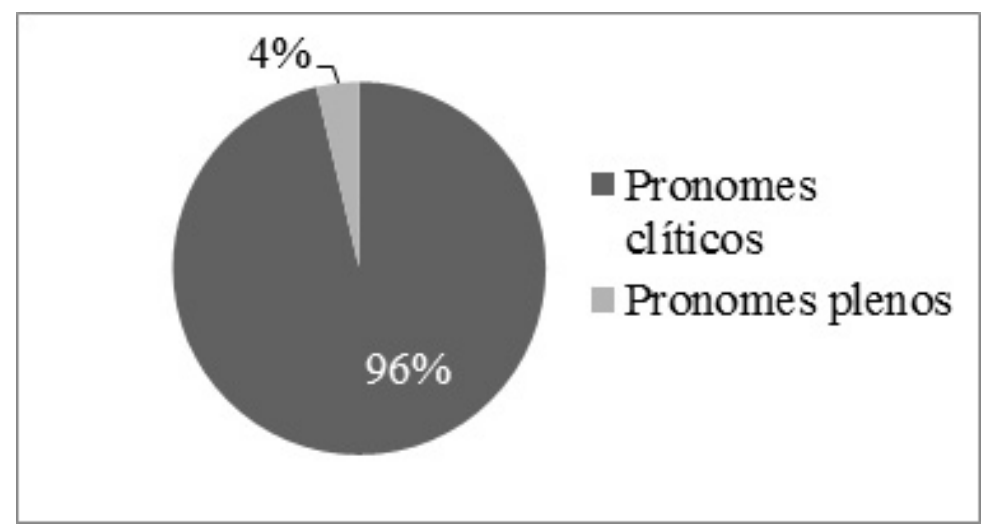

Fonte: Elaborado pelo autores. 
Ou seja, ainda há uma prevalência da norma culta de base gramatical normativa, mesmo em textos ditos "populares". Se observarmos separadamente o número de ocorrências em cada corpus, notamos que não há diferenças muito expressivas em relação à quantidade de retomadas anafóricas; por isso, optamos por amalgamar nossos dados na análise dos dois jornais, como representado na Tabela 6 .

TABELA 6 - Ocorrências totais de tipos de retomada anafórica nos corpora DG e Massa!

\begin{tabular}{c|c|c|c}
\hline \multirow{2}{*}{ Tipos de retomada } & \multicolumn{2}{|c|}{$\mathbf{N}^{\mathbf{0}}$ de ocorrências } & TOTAL \\
\cline { 2 - 4 } & Corpus Diário Gaúcho & Corpus Massa! & \\
\hline ON & $72(37,1 \%)$ & $44(31,9 \%)$ & $116(35 \%)$ \\
\hline Clíticos & $115(59,3 \%)$ & $93(67,4 \%)$ & $208(62,6 \%)$ \\
\hline Pronomes plenos & $7(3,6 \%)$ & $1(0,7 \%)$ & $8(2,4 \%)$ \\
\hline TOTAL & $194(100 \%)$ & $138(100 \%)$ & $332(100 \%)$ \\
\hline
\end{tabular}

Fonte: Elaborada pelos autores.

Poderíamos pensar que, por nossos corpora jornalísticos serem de regiões muito diferentes - Sul e Nordeste - haveria uma diferença dialetal entre eles, principalmente no que diz respeito à conservação dos clíticos. Entretanto, não é o que acontece: no corpus do Jornal Massa! há preferência por clíticos $(67,4 \%$ dos casos de retomada anafórica), assim como encontramos no corpus do Jornal Diário Gaúcho (59,3\%), de Porto Alegre. A diferença de porcentagem se deve, talvez, à diferença do número de ocorrências encontradas no total de cada corpus.

Ao analisarmos se a combinação dos traços de animacidade e especificidadedos referentes é capaz de explicar a escolha entre ON e pronome na retomada anafórica de objeto direto em nosso corpus, encontramos os resultados apresentados na Tabela 7, a seguir. 
TABELA 7 - Combinações dos traços [animacidade] e [especificidade] e ocorrências objetos nulos vs. pronomes em nossos corpora de jornais

\begin{tabular}{c|c|c}
\hline Traço do antecedente & Objeto Nulo & Pronomes \\
\hline$[+\mathrm{a},+\mathrm{e}]$ & $2(1,3 \%)$ & $\mathbf{1 5 3}(\mathbf{9 8 , 7 \% )}$ \\
\hline$[+\mathrm{a},-\mathrm{e}]$ & -- & $\mathbf{1 0}(\mathbf{1 0 0 \% )}$ \\
\hline$[-\mathrm{a},+\mathrm{e}]$ & $\mathbf{7 6}(\mathbf{7 2 , 4 \% )}$ & $29(27,6 \%)$ \\
\hline$[-\mathrm{a},-\mathrm{e}]$ & $\mathbf{3 8}(\mathbf{6 1 , 3 \% )}$ & $24(38,7 \%)$ \\
\hline
\end{tabular}

Fonte: Elaborada pelos autores.

Por um lado, os resultados mostram que a combinação desses dois traços não é a melhor hipótese para a explicação da distribuição entre pronome e $\mathrm{ON}$, uma vez que o traço de animacidade isolado responderia melhor como se dá o condicionamento da retomada anafórica do que a combinação entre os dois traços. Ou seja, o traço de especificidade se mostrou redundante, e sua influência não é clara: os referentes com o traço [+animado] são, majoritariamente, retomados por pronomes $(98,7 \%$ na segunda linha e $100 \%$ na terceira linha da tabela); já os referentes com o traço [+específico], ora são retomados por pronomes $(98,7 \%$ na segunda linha), ora, por categoria vazia ( $72,4 \%$ na quarta linha da tabela).

Por outro lado, se levarmos em consideração apenas o traço de animacidade, os casos [-animados] não são tão claros, uma vez que não formam uma classe natural opositiva, i.e., não há uma polarização tão categórica dos resultados. Em referentes [-a, -e], por exemplo, os números não esclarecem uma preferência por $\mathrm{ON}$ ou pronome muito polarizada (mais de 2/3 das ocorrências se dão com pronomes).

Uma possibilidade - e talvez uma hipótese a ser testada - é que haja cruzamento de gênero gramatical (antigo sistema dos clíticos) com gênero semântico (novo sistema do PB falado). Especificamente, em antecedentes [+animados], a forma anafórica segue o gênero gramatical do antecedente; em referentes [-animados], a forma anafórica tende a ser nula por causa da ausência de gênero semântico. $O$ que acontece em referentes [-a, -e], em que não há uma preferência clara por objetos nulos ou pronomes, deve resultar justamente da sobreposição desses dois sistemas existentes: o antigo sistema de clíticos e o novo sistema pronominal do PB falado. Isso explicaria se há uma diferença entre uso de nulos em trechos que reportam fala vs. trechos da "narrativa 
propriamente dita", mas provavelmente não é aleatório e deve haver algum fator discursivo intervindo nisso - voltaremos a essa ideia mais à frente, quando discutirmos os dados com relação ao gênero semântico do referente.

De qualquer maneira, nossos resultados em relação à combinação dos traços de animacidade e especificidade estão de acordo com as análises mencionadas na literatura, na medida em que o traço de animacidade do antecedente exerce papel importante na distribuição de pronomes e ONs em PB, e também pelo fato de que o traço de especificidade é o que menos polariza esses tipos de retomada anafórica, apesar de influenciar na escolha entre as duas formas (aqui, atua sobre os [-animados]), conforme se vê no Gráfico 4, seguir.

GRÁFICO 4 - Combinações dos traços de [animacidade] e [especificidade

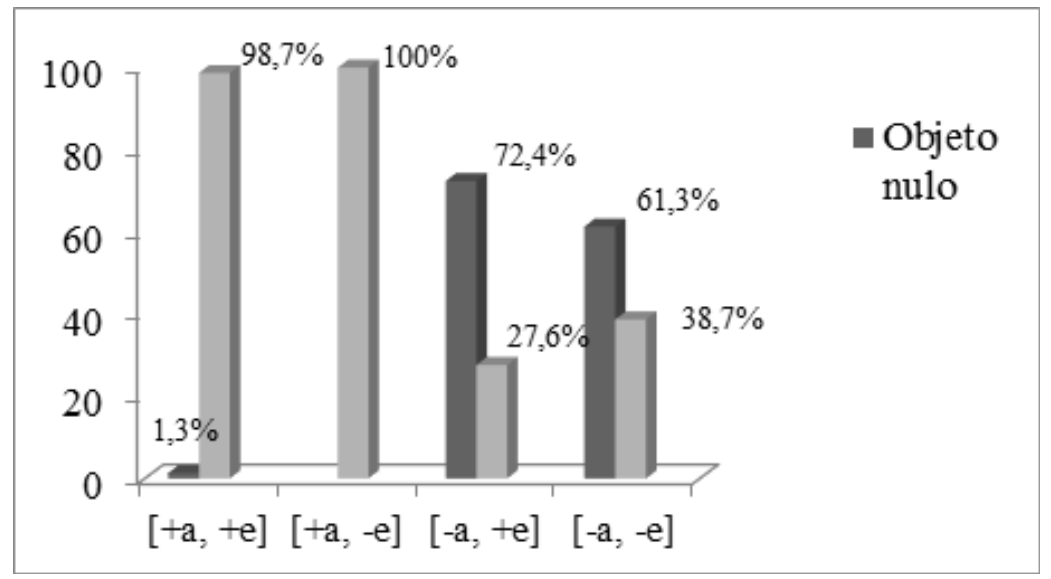

Fonte: Elaborado pelos autores

É possível observar que a interação entre esses dois traços ainda não é totalmente clara. Passemos, então, à hipótese do gênero semântico. A hipótese do gênero semântico como condicionador da escolha entre $\mathrm{ON}$ e pronome parece explicar as retomadas anafóricas em PB de uma forma mais clara: o maior número de ocorrências de pronomes acontece quando os referentes têm o traço [ $+\mathrm{gs}]$, assim como o maior número de ONs ocorre com antecedentes com o traço [-gs]. 
TABELA 8 - Traço [gênero semântico] e ocorrências objeto nulo vs. pronomes

\begin{tabular}{c|c|c}
\hline Traço do antecedente & Objeto Nulo & Pronomes \\
\hline$[+$ gs $]$ & $2(1,3 \%)$ & $\mathbf{1 4 7}(\mathbf{9 8 , 7 \% )}$ \\
\hline$[-$ gs $]$ & $\mathbf{1 1 4}(\mathbf{6 2 , 3 \% )}$ & $69(37,7 \%)$ \\
\hline
\end{tabular}

Fonte: Elaborada pelos autores.

Quando o antecedente tem o traço de gênero semântico marcado positivamente [+gs], é retomado por um pronome (é o que acontece em $98,7 \%$ dos casos); caso contrário, é preferencialmente retomado por um $\mathrm{ON}$, mesmo que de forma não categórica ( $62,3 \%$ dos casos), como ilustrado no Gráfico 5.

GRÁFICO 5 - Traço [gênero semântico] e ocorrências de objetos nulos vs. pronomes

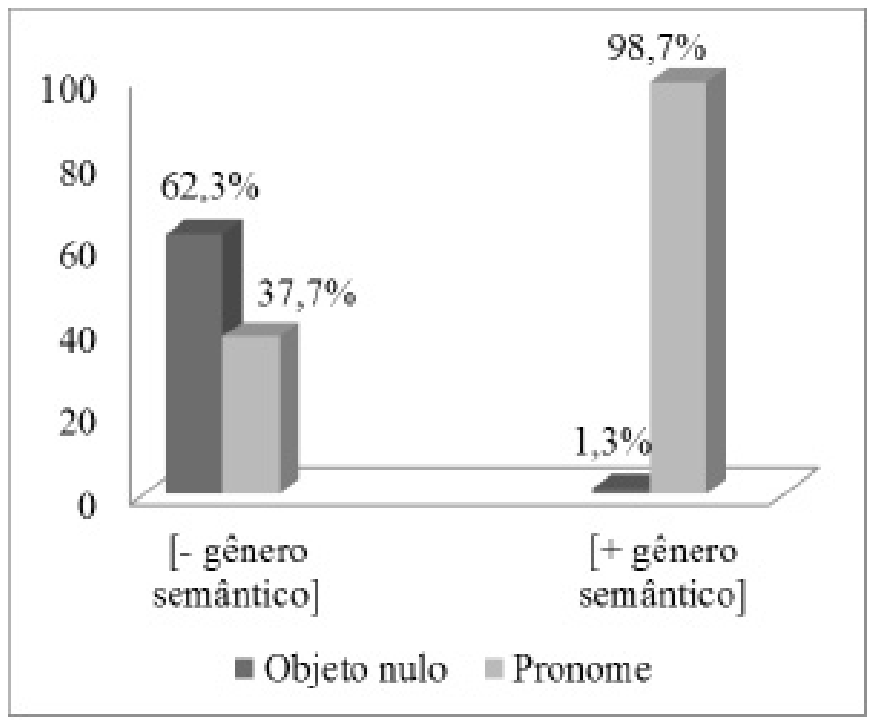

Fonte: Elaborado pelos autores.

Analisando apenas as ocorrências de ONs, dividindo-as entre as que se deram com referente com traço [-gs] e [+gs], notamos que a maioria (98,7\% dos casos) de ocorrências de ONs acontece em retomadas de antecedentes com o traço [-gs]. Nossos resultados, portanto, vão ao encontro da hipótese de Creus e Menuzzi (2004), uma vez que o traço 
de gênero semântico parece ser condicionador da retomada anafórica de objeto nulo - ao menos em nosso corpus de língua escrita popular. Ver Gráfico 6.

GRÁFICO 6 - Traço [gênero semântico] e ONs

\section{Retomadas por pronomes}

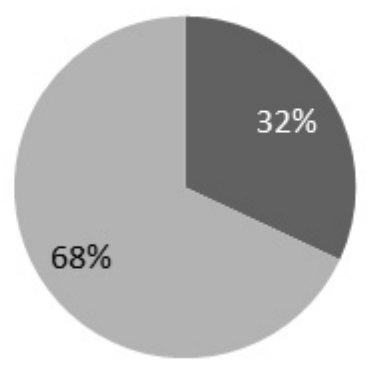

- [- gênero semântico]

[ [+ gênero semântico $]$

Fonte: Elaborado pelos autores.

Inversamente, como demonstrado no Gráfico 7, ao analisarmos apenas as retomadas anafóricas feitas por pronomes, percebemos que eles têm a tendência de recuperar antecedentes com o traço [ $+\mathrm{gs}]$. 
GRÁFICO 7 - Traço [gênero semântico] e pronomes

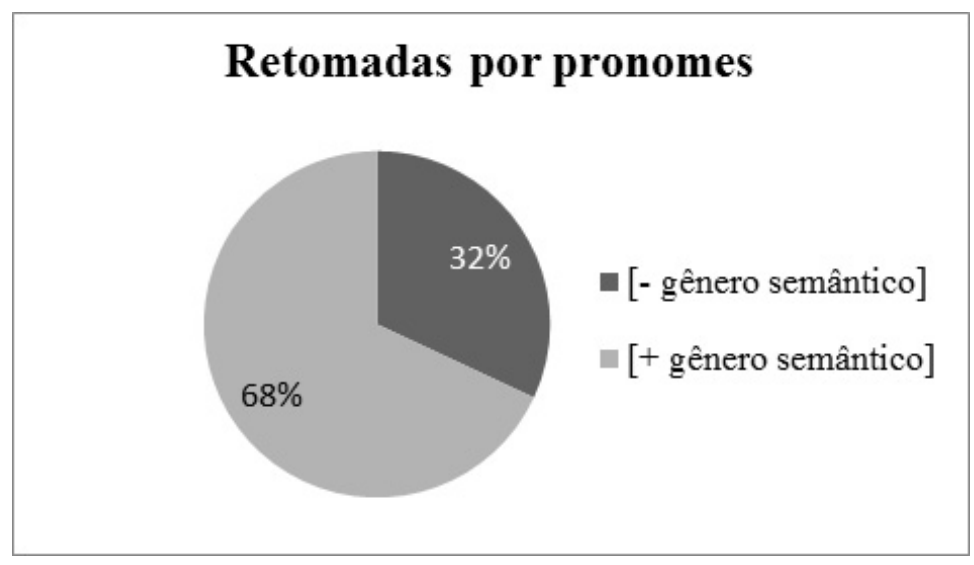

Fonte: Elaborado pelos autores.

Considerando as duas hipóteses aqui comparadas e os resultados quantitativos a que chegamos, poderíamos pensar, ainda, que apenas o traço de animacidade do antecedente explicaria o fenômeno de retomada anafórica de forma mais clara, pois, como temos alertado ao longo do texto, esse traço exerce papel de grande importância na distribuição de pronomes e ONs em PB, conforme demonstrado na Tabela 9.

TABELA 9 - Traço [animacidade] e ocorrências objeto nulo $v s$. pronomes nos corpora de jornais

\begin{tabular}{c|c|c}
\hline Traço do antecedente & ONs & Pronomes \\
\hline$[+\mathbf{a}]$ & $2(1,2 \%)$ & $\mathbf{1 6 3 ( 9 8 , 8 \% )}$ \\
\hline$[-\mathrm{a}]$ & $\mathbf{1 1 4}(\mathbf{6 8 , 3 \% )}$ & $53(31,7 \%)$ \\
\hline
\end{tabular}

Fonte: Elaborada pelos autores.

De certa forma, o traço de animacidade do referente explica, em nosso corpus, como se dá a escolha entre os tipos de retomada anafórica pesquisados, ainda que os resultados não sejam categóricos. Referentes [+animados] são quase sempre retomados por pronomes $(98,8 \%)$, enquanto referentes [-animados] são preferencialmente retomados por ONs (68,3\%), embora, em alguns casos, a retomada ocorra com pronomes $(31,7 \%)$. Esses números são muito semelhantes aos que encontramos na 
análise com o traço de gênero semântico, como podemos verificar na Tabela 10, repetida a seguir por conveniência.

TABELA 10 - Traço [gênero semântico] e ocorrências objeto nulo vs. pronomes

\begin{tabular}{c|c|c}
\hline Traço do antecedente & ONs & Pronomes \\
\hline$[+$ gs] & $2(1,3 \%)$ & $\mathbf{1 4 7}(\mathbf{9 8 , 7 \% )}$ \\
\hline$[-\mathrm{gs}]$ & $\mathbf{1 1 4}(\mathbf{6 2 , 3 \% )}$ & $69(37,7 \%)$ \\
\hline
\end{tabular}

Fonte: Elaborada pelos autores.

Os números coincidem dessa forma pelo fato de a maioria dos antecedentes ser $[+\mathrm{a},+\mathrm{gs}]$ ou [-a, -gs]. Temos, em muitos dos casos, uma quase sobreposição entre esses dois traços: referentes animados, na maioria das vezes, também são aqueles que têm gênero semântico; por outro lado, referentes [-animados] são majoritariamente [-gênero semântico].

Entretanto, aqui havíamos nos proposto a comparar as duas hipóteses correntes na literatura sobre o condicionamento da retomada anafórica em PB: a hipótese do gênero semântico versus a hipótese do traço de animacidade em conjunto com o de especificidade. A partir disso, se seguirmos o princípio da Navalha de Occam, i.e., se, entre essas duas teorias que explicam os mesmos fatos, considerarmos a mais simples como a mais adequada para explicar o fenômeno da retomada anafórica em PB, a hipótese do gênero semântico (que envolve apenas um único traço do referente) explica o condicionamento entre objeto nulo vs. pronomes de maneira mais adequada e econômica.

Também há uma vantagem conceitual para a hipótese do gênero semântico, uma vez que, como afirmam Creus e Menuzzi (2004, p. 7), estamos diante de um processo geral de anáfora. Em outras palavras, estamos tratando de um processo de concordância entre forma anafórica e antecedente: referentes com gênero semântico são retomados preferencialmente por pronomes porque esses são formas anafóricas especificadas para gênero (sejam pronomes plenos, 'ele'/'ela'; ou clíticos 'o'/'a'). Já os antecedentes sem gênero semântico favorecem a retomada por objetos nulos porque ONs são categorias não especificadas para gênero. Para a teoria baseada em animacidade, há a necessidade de um empenho maior para explicar o motivo de animados demandarem pronomes e não animados requererem objetos nulos. E, mais uma vez, o gênero semântico pode explicar o fenômeno, considerando-se o fato 
de que somente os antecedentes [+animados] podem ser associados a gênero semântico. ${ }^{13}$

Passemos à análise das ocorrências que encontramos no corpus de redações escolares. Encontramos 86 ocorrências de retomada anafórica de objeto direto de $3^{\mathrm{a}}$ pessoa, sendo 35 retomadas por ON, 26, por pronomes plenos, e 25 , por clíticos, representadas em porcentagem no Gráfico 8, a seguir. ${ }^{14}$

GRÁFICO 8 - Distribuição entre ON, pronomes plenos e clíticos no corpus de redações escolares

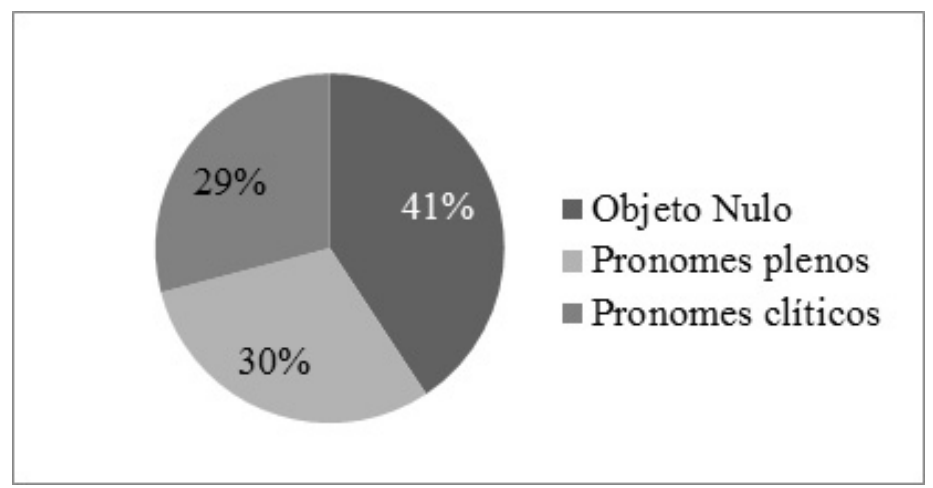

Fonte: Elaborado pelos autores.

${ }^{13}$ Othero et al. (2016, p. 78-9) chegam, mais ou menos, à mesma conclusão usando o conceito de marcação. Em suas palavras: "Nossa ideia básica é relativamente simples: baseamo-nos no fato já bastante conhecido de que o objeto direto prototípico (nas línguas humanas, de maneira geral) é um referente não animado ou não humano (assim como o sujeito prototípico é um referente animado). [...] temos em PB uma estratégia relativamente inovadora [...] para a retomada de objetos (prototipicamente inanimados e, portanto, sem gênero semântico): a retomada anafórica com uma categoria vazia, $o$ objeto nulo. Defendemos que essa é a estratégia default, não marcada. Ela é mais frequente [...], tem menos material linguístico (Ø) e é mais comum na produção de crianças em fase de aquisição da linguagem [...].Por outro lado, caso o sistema depare com um caso atípico, i.e., com um objeto direto anafórico cujo referente tem o traço [+gs], usa-se o pronome. Trata-se da conhecida condição de Else where [...]: o uso de uma forma mais específica se aplica antes de uma forma mais genérica (a forma menos marcada, objeto nulo, sendo a menos específica)". Grifos dos autores.

${ }^{14}$ Encontramos apenas 9 ocorrências de elipses de VP e optamos por não contabilizá-las em nossa análise, uma vez que o cerne do nosso trabalho está no fenômeno do objeto nulo em PB, como já advertimos. 
Os dados mostram que o objeto nulo é a estratégia de retomada preferida pelas crianças - cenário distinto daquele encontrado na escrita jornalística que pesquisamos, ainda que também distinta dos dados de fala de crianças, que demonstram ser o $\mathrm{ON}$ a principal estratégia de retomada anafórica do objeto, como mostram, por exemplo, os dados de Ayres (2016, p. 36), que investigou o fenômeno de retomada anafórica do objeto em corpus de língua falada infantil: $76,1 \% \mathrm{ON}, 5,6 \%$ pronome pleno, $1,8 \%$ clíticos. Entretanto, ao agruparmos a classe dos pronomes (plenos + clíticos), a situação se inverte. De toda sorte, em termos percentuais, há mais ONs na escrita infantil do que na escrita jornalística popular.

Também podemos constatar aqui que o traço de animacidade é relevante para o condicionamento entre ON e pronome (ver Tabela 11). Já os referentes com o traço [ \pm específico] ora são retomados por pronomes, ora por categoria vazia.

TABELA 11 - Traços de [animacidade] e [especificidade] no corpus de redações escolares

\begin{tabular}{c|c|c|c}
\hline Traços do antecedente & ONs & Pronomes & TOTAL \\
\hline$[+\mathrm{a},+\mathrm{e}]$ & $9(19,6 \%)$ & $\mathbf{3 7}(\mathbf{8 0 , 4 \% )}$ & 46 \\
\hline$[+\mathrm{a},-\mathrm{e}]$ & $1(25 \%)$ & $\mathbf{3}(\mathbf{7 5 \%})$ & 4 \\
\hline$[-\mathrm{a},+\mathrm{e}]$ & $\mathbf{1 5}(\mathbf{7 1 , 4 \% )}$ & $6(28,6 \%)$ & 21 \\
\hline$[-\mathrm{a},-\mathrm{e}]$ & $\mathbf{1 0}(\mathbf{6 6 , 7 \%})$ & $5(33,3 \%)$ & 15 \\
\hline
\end{tabular}

Fonte: Elaborada pelos autores.

Os dados de referentes [-animados] são semelhantes ao que encontramos no corpus de textos jornalísticos; todavia, com os referentes [+animados] a situação é bem menos polarizada. Ou seja, se analisarmos esses dados com base na hipótese dos traços de animacidade e especificidade, estaremos recaindo sobre os mesmos problemas já citados anteriormente, quando analisamos os textos jornalísticos: a interação entre os dois traços não nos fornece uma explicação clara, nem resultados categóricos para o fenômeno da retomada anafórica.

Da mesma maneira, se analisarmos o corpus levando-se em conta a hipótese de gênero semântico, o condicionamento da escolha entre $\mathrm{ON}$ e pronomes fica mais claro: antecedentes com o traço [+gs] favorecem pronomes, enquanto referentes [-gs] favorecem ONs, conforme demonstrado na Tabela 12. 
TABELA 12 - [gênero semântico] no corpus de redações escolares

\begin{tabular}{c|c|c}
\hline Traço do antecedente & ONs & Pronomes \\
\hline$[+\mathrm{gs}]$ & $3(8,6 \%)$ & $\mathbf{3 2}(\mathbf{9 1 , 4 \% )}$ \\
\hline$[-\mathrm{gs}]$ & $\mathbf{3 2}(\mathbf{6 2 , 7 \% )}$ & $19(37,3 \%)$ \\
\hline
\end{tabular}

Fonte: Elaborada pelos autores.

Ainda que os resultados também não sejam tão polarizados (em referentes com o traço [-gs], por exemplo, temos $62,7 \%$ de ON vs. 37,3\% de pronomes), a hipótese do gênero semântico continua explicando o fenômeno de retomada anafórica em PB de uma forma mais econômica, por meio de um único traço, e, principalmente, de uma forma mais natural, pois trata-se simplesmente de um processo geral de anáfora, no qual a forma anafórica (ON ou pronome) concorda com seu antecedente. Os dados que encontramos ao reanalisar o corpus de Oliveira (2007) contribuem para nossa pesquisa na medida em que são semelhantes aos resultados a que chegamos com os corpora do Projeto PorPopular, indicando que o gênero semântico parece ser o traço condicionador da retomada anafórica de objeto nulo. (Ver Gráficos 9 e 10)

GRÁFICO 9-ONs no corpus de redações escolares

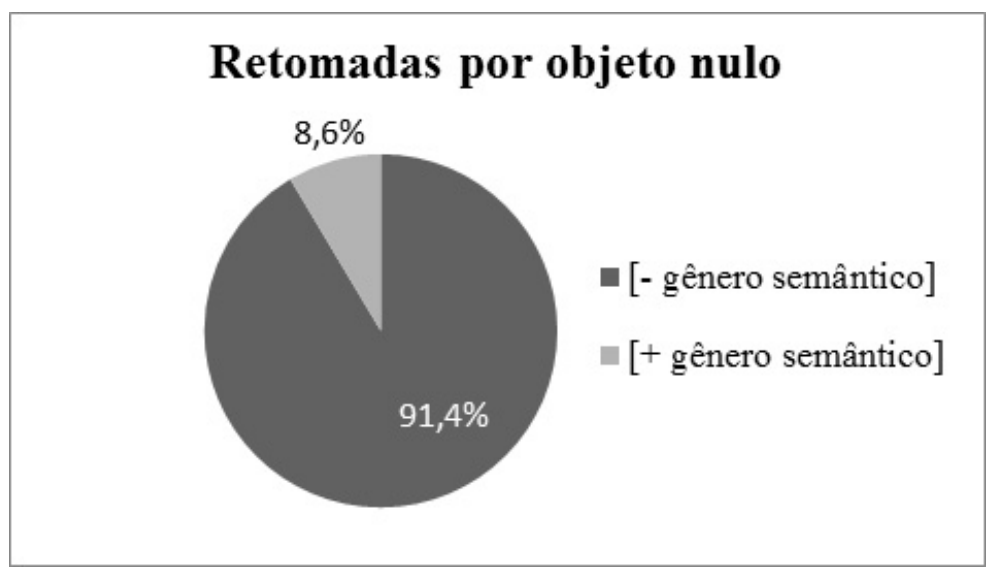

Fonte: Elaborado pelos autores. 
GRÁFICO 10 - Pronomes no corpus de redações escolares

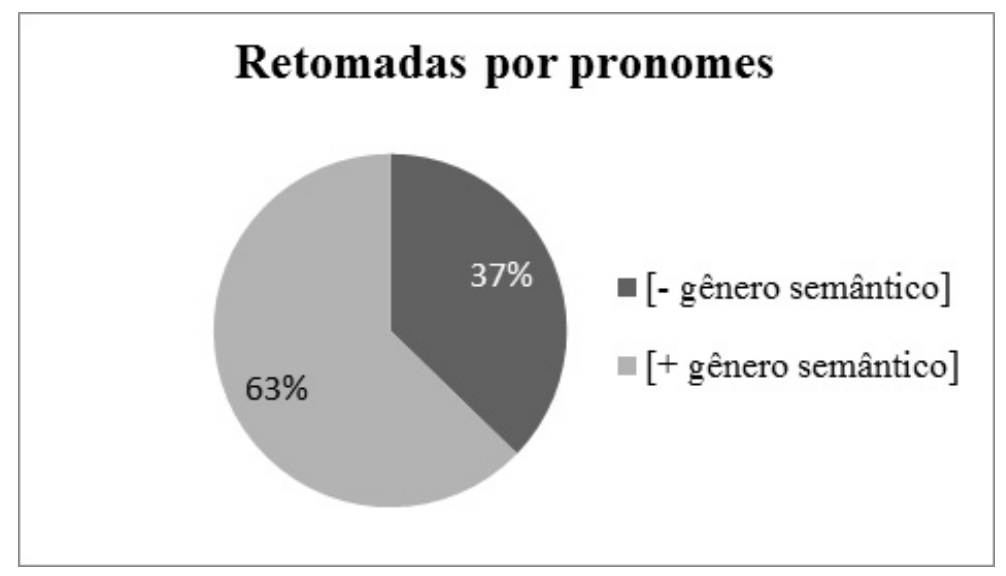

Fonte: Elaborado pelos autores.

Além disso, os dados do corpus de redações infantis escolares, assim como os resultados já apresentados por Oliveira (2007), nos mostram que o clítico ainda é muito usado pelas crianças como forma anafórica na língua escrita: seu uso começa a aparecer nos dados textuais apenas nas séries finais, à medida que o grau de escolarização e normatização em que a criança está inserida vai aumentando, conforme se demonstra na Tabela 13.

TABELA 13 - Ocorrências de pronomes clíticos de $3^{\mathrm{a}}$ pessoa em relação à série da criança

\begin{tabular}{c|c}
\hline \multicolumn{2}{c}{ Clíticos acusativos de $\mathbf{3}^{\mathrm{a}}$ pessoa } \\
\hline Série & $\mathbf{N}^{\mathbf{o}}$ de ocorrências \\
\hline $1^{\mathrm{a}}$ & $3(8 \%)$ \\
\hline $2^{\mathrm{a}}$ & $8(16 \%)$ \\
\hline $3^{\mathrm{a}}$ & $5(11 \%)$ \\
\hline $4^{\mathrm{a}}$ & $14(34 \%)$ \\
\hline Total & $30(100 \%)$ \\
\hline
\end{tabular}

Fonte: Elaborada pelos autores 
Em suma, o papel da escolarização mantêm os clíticos de $3^{\mathrm{a}}$ pessoa como parte do quadro pronominal em PB, o que explica o fato de termos quase ausência de pronomes plenos (em função de objeto direto) em nossos corpora de jornais (em oposição à larga ocorrência de pronomes clíticos). Ainda que sejam considerados jornais da mídia impressa dita "popular", são, antes de tudo, textos monitorados e revisados de acordo com a norma gramatical tradicional.

Na próxima seção, veremos os casos de antecedentes [-gs] que são retomados por pronomes, ou seja, casos de "exceção" às predições da hipótese do gênero semântico.

\subsection{Discussões interessantes}

Nesta seção, abordaremos os dados encontrados que não "se comportam" de acordo com as previsões da hipótese do gênero semântico, i.e., casos em que antecedentes [-gs] são retomados por pronomes e casos em que antecedentes [ $+\mathrm{gs}]$ são retomados por objeto nulo. Muitos desses "casos destoantes" são retomadas anafóricas influenciadas por princípios discursivos particulares outros que não os traços do referente.

\subsubsection{Análise dos casos "destoantes" com pronomes}

Ainda que tenhamos concluído que a hipótese do traço de gênero semântico seja a mais adequada para explicar a retomada anafórica de objeto direto de $3^{\mathrm{a}}$ pessoa em $\mathrm{PB}$ escrito, não encontramos resultados polarizados, i.e., nossos resultados não nos possibilitaram estabelecer classes naturais opositivas claras. Isso talvez se deva ao fato de que encontramos muitas ocorrências de referentes com o traço [-gs] sendo retomados por pronome, quando o esperado era a retomada anafórica realizada com objeto nulo.Vejamos a Tabela 10 novamente.

TABELA 10 - Traço [gênero semântico] e ocorrências objeto nulo vs. pronomes

\begin{tabular}{c|c|c}
\hline Traço do antecedente & Objeto Nulo & Pronomes \\
\hline$[+\mathrm{gs}]$ & $2(1,3 \%)$ & $\mathbf{1 4 7}(\mathbf{9 8 , 7 \% )}$ \\
\hline$[-\mathrm{gs}]$ & $\mathbf{1 1 4}(\mathbf{6 2 , 3 \% )}$ & $69(37,7 \%)$ \\
\hline
\end{tabular}

Fonte: Elaborada pelos autores. 
Com o traço $[+\mathrm{gs}]$, os resultados são bem polarizados: 98,7\% de retomadas feitas com pronomes. Já os referentes [-gs] são preferencialmente retomados com $\mathrm{ONs}$, mas não encontramos aí um resultado categórico, visto que, em pouco mais de um terço dos casos, a retomada anafórica foi realizada com pronome. Se levarmos em consideração a ideia de que há sobreposição entre dois sistemas no PB, o grande número de clíticos retomando referentes [-gs] pode indicar que o antigo sistema ainda está se manifestando em resíduo - ou seja, o clítico (como forma conservadora de retomada anafórica de objeto) ainda se mantém. De qualquer maneira, analisando cada caso isoladamente, chegamos à hipótese de que, nessas ocorrências, a retomada anafórica foi feita com um pronome devido a questões discursivas particulares. Organizamos esses casos em três categorias distintas: (i) concordância ideológica, (ii) referência a grupos (coletivos) e (iii) acessibilidade do referente.

\section{Concordância ideológica}

É o tipo de concordância que se faz pelo sentido e, por isso, é também denominada "concordância de palavra para sentido" (BECHARA 2009 , p. 555). Encontramos três casos de retomada anafórica com concordância ideológica, todos com referentes [-gs] e retomados por pronomes, o que nos leva a crer que, nos casos desse tipo de concordância, a tendência é que o pronome seja mantido.

(10) A Defensoria Pública procurou a família para auxiliá-los nesta questão.

(11) Prometi que se ele ficasse bom, eu faria uma festa no Natal com a gurizada da vila. [...] Com o tempo e a ajuda de vizinhos e voluntários anônimos, a festa cresceu. (...) Os doadores não apareceram. Estou preocupada, mas não vou desistir. Se for preciso sairei só com o saco vazio para animá-los.

(12) No entanto, contou que pagou R $\$ 300$ pelo revólver calibre 38 na Feira do Pau, há um mês e a deixou guardada.

Em (10) e (11), há concordância ideológica de número: a informação semântica de plural presente nos antecedentes 'a família' e 'a gurizada' influencia na retomada anafórica, acionando o plural na 
retomada com pronome eestabelecendo concordância. Já em (12), a concordância é de gênero, pois a informação semântica subentendida em 'revólver calibre 38' é a de que este objeto é hipônimo de 'arma' e, portanto, a concordância foi feita com o gênero feminino do hiperônimo 'arma'.

\section{Grupos (coletivos)}

Em nossos dados, seis casos de referentes [-gs] retomados por pronomes se encaixam nessa categoria, i.e., todos os antecedentes, nesse caso, fazem denotação a um grupo de pessoas ou coletivos de indivíduos específicos:

(13) Dependemos de encontrar médicos [...] mas não conseguimos atraí-los.

(14) A enfermeira explica que atividades como essa são fundamentais para trazer alegria aos idosos e também para quem trabalha na casa.

- Essa tarde deixou eles de alma lavada. E para nós, funcionários, é como se a gente pudesse se reenergizar.

(15) Conseguimos separar um elenco legal, na parte vocal, e enquadrálo nas vozes de cada personagem.

Em (13) e (14), "médicos" e "os idosos" recebem o traço [-gs] porque fazem referência a grupos ainda não estabelecidos e que podem ser formados por homens e mulheres; por isso, não conseguimos identificar o sexo natural (gênero semântico) nesses referentes. Também em (15) temos uma situação semelhante, em que o referente "um elenco geral" denota o coletivo de atores e, portanto, tem o traço [-gs]. Na verdade, todos os casos que encontramos (seis casos) desse tipo foram retomados por pronome (e não $\mathrm{ON}$, como esperávamos). Em todos esses casos, trata-se de concordância gramatical, o que pode comprovar-caso seja feita uma análise mais aprofundada - a hipótese de que, em casos de referentes [+animados], a influência maior é do gênero gramatical, e não semântico. 


\section{Acessibilidade do referente}

Em 18 ocorrências do corpus, a retomada anafórica de um antecedente [-gs] foi realizada com pronome por uma questão de acessibilidade do referente. Em outras palavras, o pronome foi mantido para identificar o antecedente correto, por uma questão de distância entre anáfora e referente ou por competição com outros possíveis antecedentes. Em (16), por exemplo, a acessibilidade do referente poderia ficar comprometida caso fosse usada uma categoria vazia na função de objeto (há outros referentes possíveis no meio do período, como 'o local' e 'a prova').

(16) O participante receberá até 18 de agosto, no endereço indicado na inscrição, o cartão de confirmação com $o$ local onde fará $a$ prova. Se não recebê-lo até esta data, o inscrito deverá procurar os Correios.

O exemplo a seguir é ainda mais claro:

(17) Sempre que vê o celular do pai, o pintor automotivo Seriano Vargas, 25 anos, dando sopa no bolso da calça, pega-o para jogar um pouquinho.

A quantidade de informações em uma mesma frase, como em (16), faz surgir a necessidade de pronome na retomada anafórica, mesmo que o antecedente seja [-gs]. Amaral (2004) assume a hipótese da topicalidade discursiva para solucionar os casos "anômalos" de Schwenter e Silva (2003), em que os referentes foram retomados com pronomes quando suas propriedades pareciam indicar o uso de ON. Segundo Amaral (2004, p. 1), os referentes pronominais não se limitam às características semântico-pragmáticas, mas a estrutura discursiva também desempenha papel relevante: "as características do discurso se sobrepõem aos traços semântico-pragmáticos quando a coerência discursiva está em jogo".

O grau de coerência discursiva está relacionado à dificuldade de processamento de um texto. Como certos elementos de um dado enunciado são mais centrais que outros, se esse elemento central é tratado de forma diferente no enunciado seguinte, há um impacto na coerência do discurso, i.e., se o centro do discurso muda, aumenta a 
carga de inferência de que o leitor precisa para processar corretamente o enunciado (cf. AMARAL, 2004), como em (18).

(18) O João ensina inglês.

Ele é muito bom professor para o Paulo.

Ele explica a matéria com clareza.

Ele está aprendendo muito rápido. (exemplo de AMARAL, 2004, p. 3)

Até a terceira frase de (18), identificamos "O João" como o elemento central. Quando esse centro muda (e, nesse caso, a forma anafórica continua a mesma), é mais difícil identificar qual referente é o foco do discurso; assim, a última frase se torna menos coerente: "a forma do objeto direto anafórico selecionada pelo falante reflete seu desejo de marcar um determinado elemento como possível tópico do discurso"(AMARAL, 2004, p. 7).

(19) Soube, tempos depois, que havia perdido uma oportunidade de emprego devido a meu cabelo. Mas lembro que, naquela época, éramos todas contra o alisamento. Naquela época, o corte era bem definido. Cortado com precisão. Para penteá-lo, era usado o chamado garfo.

Em (19), "o meu cabelo" ([-gs]) foi introduzido como tópico na primeira frase. Depois, a entrevistada pelo jornal comenta sobre os costumes da época e decide reintroduzir "o meu cabelo" como tópico, utilizando, para isso, o pronome como forma de retomada anafórica, em vez do objeto nulo, reforçando o tópico do discurso e facilitando a acessibilidade do referente. Outro exemplo:

(20) Ao contrário do que as empresas de telefonia afirmaram, a AesSul afirma que o poste em questão é, sim, de responsabilidade deste serviço. O Diário Gaúcho se compromete a procurá-las, para identificar quem deve fazer a troca.

Em (20), temos um caso semelhante. Aqui a acessibilidade do referente ficaria comprometida caso tivesse sido utilizada uma forma nula na posição de objeto, já que há outros referentes possíveis no meio 
do trecho (como "a AesSul", "o poste" ou "este serviço"). Se o redator escolhesse uma forma nula, não conseguiria indicar para o seu leitor a mudança no tópico discursivo, e os sujeitos dos últimos enunciados seriam mais salientes.

\section{Análise dos casos "destoantes" com ONs}

É interessante destacar que $63,8 \%$ dos referentes retomados com ONs estão dentro de alguma fala (no discurso direto), indicando que esse tipo de retomada anafórica é, realmente, frequente em língua falada (de todo modo, o ON também já está presente de maneira significativa em língua escrita padrão, pois $36,2 \%$ das ocorrências de ON apareceram no corpo do texto dos jornais).

Encontramos apenas dois casos que consideramos "anômalos", em que a retomada de um antecedente com o traço [+gs] foi feita com objeto nulo, em vez do pronome, como esperado. Novamente, questões discursivas parecem estar em jogo, e uma análise motivada pela topicalidade, como propõe Amaral (2004), nos permite chegar a uma explicação para esses casos.

Se o elemento [ $+\mathrm{gs}]$ já está estabelecido como tópico do discurso, i.e., se outros elementos no enunciado asseguram a topicalidade do discurso, o falante (nesse caso, o redator) pode optar por uma forma nula sem "dar indicações errôneas ou permitir falsos julgamentos sobre o centro do discurso" (AMARAL, 2004, p. 7). É o que vemos em (21), pois “o pequeno Pedro Machado Borgmann” é colocado como o elemento central e se mantém como tópico do discurso ao longo de todo o enunciado. Ao final, é retomado com $\mathrm{ON}$, uma vez que seu status de tópico já está assegurado.

(21) Quando chega da creche, no final da tarde, o pequeno Pedro Machado Borgmann, quatro anos, já tem estabelecida sua rotina: se divertir com os joguinhos do tablet até a hora da janta.

Em agosto, quando completou quatro anos, Pedro abriu mão de uma festa de aniversário com o tema do SuperMan para ganhar o tablet de presente. Teve uma comemoração simples na creche e, desde então, desliza os polegares e indicadores na tela do computador portátil. Envolvido com a brincadeira digital, chega a pedir silêncio à mãe. Afinal, precisa de concentração. Acha sozinho jogos e aplicativos, vai movendo os personagens, 
derrubando obstáculos. De tão quietinho, quase nem se nota a presença em casa, e ele nem ouve a mãe chamar $\emptyset$.

Para Amaral (2004, p. 7),

Se um elemento anafórico que é tópico do discurso tem um referente que apresenta as propriedades de um possível tópico, e se outras características do discurso garantem que este elemento seja o tópico, o falante pode optar por uma forma menos marcada para sua realização.

Em (22), vemos que nossa outra ocorrência de referente [+gs] retomado com objeto nulo parece reforçar essa hipótese. O tópico central, "Daniel de Moura Ribeiro", é assegurado por outros elementos discursivos, como "o menino esperto", para, então, ser retomado com uma categoria vazia.

(22) É até difícil de acreditar que Daniel de Moura Ribeiro tenha apenas quatro anos. Com $41 \mathrm{~kg}$ distribuídos em seu $1,15 \mathrm{~m}$ de altura, o menino esperto preocupa a família pelo excesso de peso. Em acompanhamento com um pediatra de Viamão, onde mora, os exames do menino revelam que ele precisa de uma atenção especial. [...]

Isso está, inclusive, documentado na carteirinha de saúde do menino. [...] Além do atendimento com um endocrinologista, Daniel também foi encaminhado, com urgência, no final de julho, para uma consulta com neurologista pediátrico. [...]

- Ele tá muito agitado, precisa tomar remédio para dormir. Como vai ser quando ele tiver de ir para a escola no ano que vem? preocupa-se a bisavó.

Conforme a secretária de saúde de Viamão, Sandra Sperotto, e de acordo com comprovantes enviados ao jornal, o agendamento com o especialista foi correto. No entanto, o médico teria se negado a atender $\boldsymbol{\emptyset}$.

Assim, nos parece que, além do traço de gênero semântico do antecedente, questões discursivas e contextuais em que ocorre a retomada anafórica de objeto direto também são relevantes para explicar como se dá a escolha entre pronome e $\mathrm{ON}$ na escrita em $\mathrm{PB}$. 


\section{Considerações finais}

Neste trabalho, investigamos a retomada do objeto direto de $3^{\mathrm{a}}$ pessoa em $\mathrm{PB}$, especificamente em língua escrita, e procuramos averiguar se as estratégias relativamente inovadoras e mais comuns em língua falada - pronomes plenos e ONs - já estão presentes de maneira significativa em língua escrita. Para isso, analisamos dois corpora de jornais populares e um corpus de redações escolares (e classificamos os referentes das retomadas anafóricas com base nos traços de animacidade, especificidade e gênero semântico).

Buscamos analisar nossos dados considerando as duas hipóteses existentes na literatura sobre o condicionamento da retomada anafórica de objetos diretos em PB, a saber, a hipótese dos traços de animacidade e especificidade e a hipótese do gênero semântico, para, então, contrastar os resultados encontrados e chegarmos a uma explicação mais clara para o fenômeno de retomada anafórica.

Em primeiro lugar, verificamos que o pronome clítico tem a tendência de se manter no discurso escrito, ao contrário do que acontece com a fala vernacular em PB, indicando que o grau de escolarização e normatização ainda é muito forte na mídia impressa. O clítico também é bastante usado pelas crianças como forma anafórica na língua escrita, aparecendo nos dados textuais nas séries finais, à medida que o grau de escolarização e normatização em que a criança está inserida vai aumentando.

Ainda assim, quando encontramos ONs, a hipótese do gênero semântico parece explicar o fenômeno de retomada anafórica de uma forma mais econômica (em contraste com a hipótese de animacidade e especificidade), com base em um único traço (princípio da Navalha de Occam) e, principalmente, de uma forma mais natural, pois, nesse caso, estamos diante de um processo geral de anáfora, no qual forma anafórica $\mathrm{ON}$ ou pronome) concorda com seu antecedente.

Por fim, discutimos alguns casos que não "se comportam" de acordo com as previsões da hipótese do gênero semântico, acreditando que esses "casos destoantes" sejam retomadas anafóricas influenciadas por princípios discursivos particulares. Esperamos que nosso trabalho tenha contribuído para os estudos do fenômeno em PB, principalmente em língua escrita padrão contemporânea e língua jornalística popular. 


\section{Agradecimentos}

Agradecemos a Sergio Menuzzi e Mônica Rigo Ayres por terem lido uma versão prévia deste texto e nos terem fornecido boas orientações sobre nosso trabalho.

\section{Referências}

AMARAL, L. A. A forma do objeto direto em português - uma análise motivada pela topicalidade. In: CONGRESSO NACIONAL DE LINGUÍSTICA E FILOLOGIA, VIII, 2004. Anais... Rio de Janeiro: UERJ, 2004.

AYRES, M. R. Aspectos condicionadores do objeto nulo e do pronome pleno em português brasileiro: uma análise da fala infantil. 2016. 63f. Dissertação (Mestrado) - PUCRS, Porto Alegre, 2016.

BAGNO, M. Gramática pedagógica do português brasileiro. São Paulo: Parábola Editorial, 2011.

BECHARA, E. Gramática Escolar da Língua Portuguesa. Rio de Janeiro: Lucerna, 2006.

CAMARA JR., J. M. Princípios de Linguística Geral. Rio de Janeiro: Livraria Acadêmica, 1959.

CASAGRANDE, S. A aquisição do objeto direto anafórico em português brasileiro. 2007. Dissertação (Mestrado) - UFSC, Florianópolis, 2007.

CASAGRANDE, S. Restrições de ocorrência do objeto direto anafórico no Português Brasileiro: gramática adulta e aquisição da linguagem. ReVEL, edição especial, n. 6, p. 131-163, 2012.

CREUS, S; MENUZZI, S. O papel do gênero na alternância entre objeto nulo e pronome pleno em português brasileiro. Revista da ABRALIN, Florianópolis, v. 3, n. 1-2, p. 149-176, 2004.

CYRINO, S. M. Observações sobre a mudança diacrônica no português do Brasil: objeto nulo e clíticos. In: ROBERTS, I.; KATO, M. A. (Org.). Português brasileiro: uma viagem diacrônica. Campinas: Ed. da Unicamp, 1993. 
CYRINO, S. M. O objeto nulo no português do Brasil: um estudo sintático-diacrônico. 1997. Tese (Doutorado) - UNICAMP, Campinas, 1994. [Publicada em 1997 pela Ed. da Universidade Estadual de Londrina].

CYRINO, S. M.; MATOS, G. VP ellipsis in European and Brazilian Portuguese - a comparative analysis. Journal of Portuguese Linguistics, Ubiquity Press, v. 1, n. 2, p. 177-195, 2002. Doi: https://doi.org/10.5334/ jpl.41

CYRINO, S. M.; MATOS, G. Null Objects and VP Ellipsis in European and Brazilian Portuguese. In: WETZWLS, W.; MENUZZI, S.; COSTA, J. (Org.). The Handbook of Portuguese Linguistics. Oxford: WileyBlackwell, 2016. Doi: https://doi.org/10.1002/9781118791844.ch16

DUARTE, M. E. L. Clítico acusativo, pronome lexical e categoria vazia no português do Brasil. In: TARALO, F. (Org.). Fotografias sociolinguísticas. Campinas: Pontes/Ed. da UNICAMP, 1989.

DUARTE, M. E. L. Do pronome nulo ao pronome pleno: a trajetória do sujeito no português do Brasil. In: ROBERTS, I.; KATO, M. A. (Org.). Português brasileiro: uma viagem diacrônica. Campinas: Ed. da Unicamp, 1993.

KENEDY, E. O status da norma culta na língua-i dos brasileiros e seu respectivo tratamento na escola: algumas contribuições de estudos formalistas à educação. In: GUESSER, S. (Org.). Linguística: pesquisa e ensino. Boa Vista: EDUFRR, 2016.

MATOS, G.; CYRINO, S. Elipse de VP no português europeu e no português brasileiro. Boletim da Abralin, v. 26, número especial, 2001.

MILESKI, I. Uma discussão sobre condicionamentos semânticos do uso do objeto nulo no português brasileiro. Via Litterae, Anápolis, v. 6, n. 2, 2014.

MONTEIRO, J. L. Pronomes pessoais. Fortaleza: Edições UFC, 1994.

NUNES, J. Direção de cliticização, objeto nulo e pronome tônico na posição de objeto em português brasileiro. In: ROBERTS, I.; KATO, M. (Org.). Português Brasileiro: uma viagem diacrônica. Campinas: Ed. da Unicamp, 1993. 
OLIVEIRA, S. M. Objeto direto nulo, pronome tônico de $3^{\text {a }}$ pessoa, SN anafórico e clítico acusativo no português brasileiro: uma análise de textos escolares. ReVEL, v. 5, n. 9, 2007.

OTHERO, G. A.; AYRES, M. R.; SCHWANKE, C.; SPINELLI, A. C. A relevância do traço gênero semântico na realização do objeto nulo em português brasileiro. Working Papers em Linguística, UFSC, v. 17, n. 1, p. 64-85, 2016. Doi: http://dx.doi.org/10.5007/1984-8420.2016v17n1p64

OTHERO, G. A.; CARDOZO, R. W. A ordem pronominal em português brasileiro: da ênclise à próclise, do clítico ao tônico (or There and Back Again, a Word Order's Holiday). Fórum Linguístico, UFSC, v. 14, n. 1, p. 1717-1734, 2017. Doi: http://dx.doi.org/10.5007/19848412.2017v14n1p1717

TARALLO, F. Relativization Strategies in Brazilian Portuguese. 1983. Dissertation (Doctoral) - Univ. of Pennsylvania, Philadelphia, 1983.

PIVETTA, V. Objeto direto anafórico no português brasileiro: uma discussão sobre a importância dos traços semântico-pragmáticosanimacidade/especificidade vs. gênero semântico. 2015. Dissertação (Mestrado) - UFRGS, 2015.

SCHWENTER, S.; SILVA, G. Overt vs. null direct objects in spoken Brazilian Portuguese: a semantic/pragmatic account. Hispania, The American Association of Teachers of Spanish and Portuguese v. 85, n. 3, p. 577-586, 2002.

SCHWENTER, S. A.; SILVA, G. Anaphoric direct objects in spoken Brazilian Portuguese: semantics and pragmatics. Revista Internacional de Lingüística Iberoamericana, Iberoamericana Vervuert, v. 2, p. 109133, 2003.

VIEIRA-PINTO, C. A.; COELHO, I. L. O objeto direto anafórico de SN: uma análise da fala de Florianópolis em duas sincronias. ReVEL, edição especial, n. 13, p. 245-263, 2016. 